\title{
Ultradünn - auch bei der Pulverbeschichtung
}

\author{
Dünn, dünner, ultradünn - Pulverbeschichtungen mit einer Dicke von nur 20 bis $40 \mu \mathrm{m}$ sind \\ realisierbar. Sie erschließen in verschiedenen Anwendungen Vorteile. Außerdem fördern sie \\ die Ressourceneffizienz. Ihr Geheimnis liegt in der Rezeptierung ...
}

Die Pulverbeschichtung wird in der Regel mit Schichtdicken von 60 bis 120/180 $\mu$ m aufgebracht. Wenn die Schichtdicken zwischen 30 und $50 \mu \mathrm{m}$ betragen [1], wird von Dünnschichtpulver gesprochen. Dünnschichtpulver sind in der Branche schon länger im Einsatz. Die Holzapfel Group kann nun jedoch auch eine ultradünne Pulverbeschichtung mit circa 20 bis $40 \mu \mathrm{m}$ aufbringen.

\section{Für besondere technische Anforderungen}

Besonders interessant ist diese extrem dünne Pulverbeschichtung, wenn Passgenauigkeit gefordert ist. Dies kann etwa der Fall sein, wenn Bauteile mit anderen

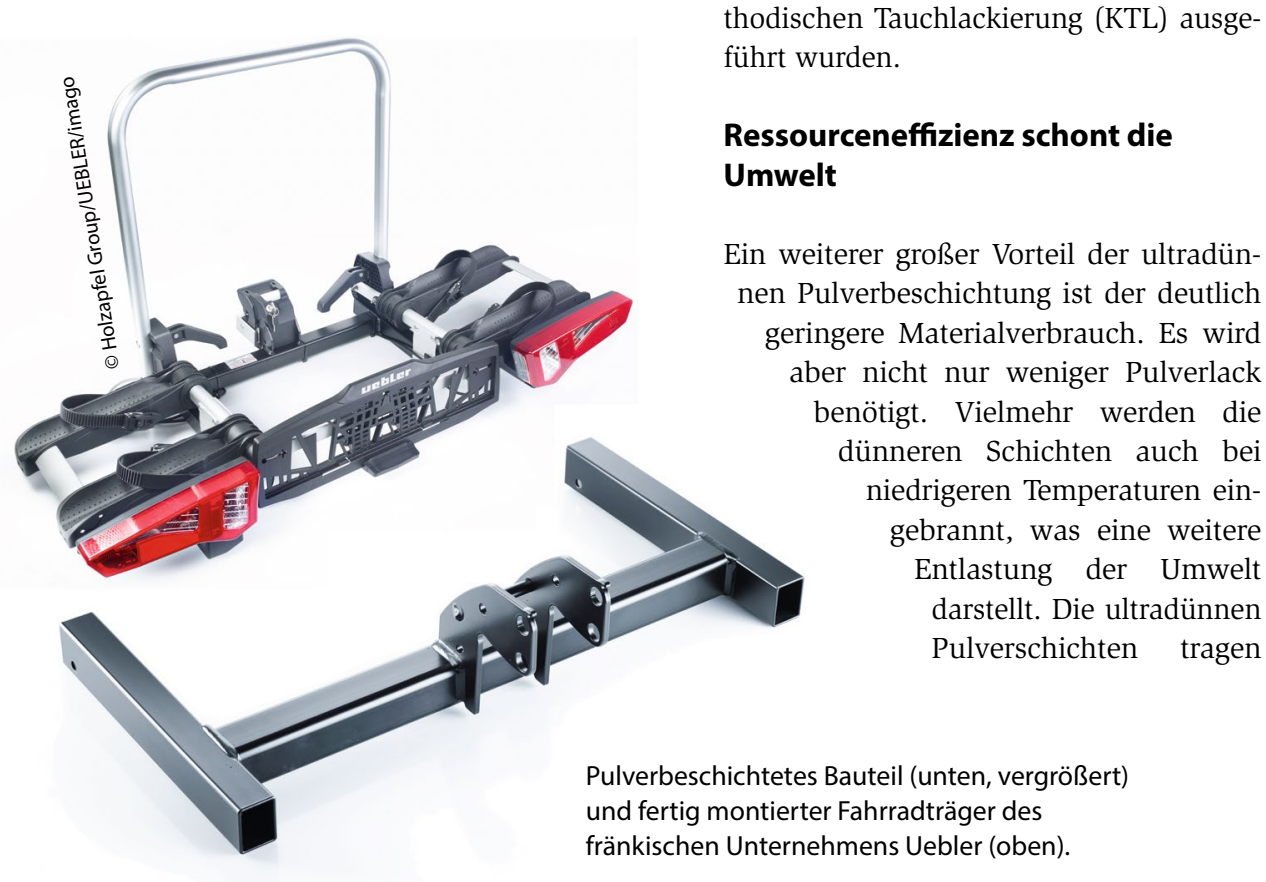

verbaut werden und die Passung gewährleistet werden muss. Auch bei anderen technischen Anforderungen wie offen $\mathrm{zu}$ haltende Feinlochungen oder Gewindebolzen, die nicht abgedeckt werden, bietet sich die dünne oder ultradünne Pulverbeschichtung an. In diesen Einsatzfällen hilft die präzise Beschichtung, Passmaße einzuhalten und die Funktionsfähigkeit zu gewährleisten. Die ultradünnen Pulverschichten überzeugen dabei laut Anbieter durch hervorragende Verlaufseigenschaften. Da je nach Anwendungsfall kein $\mathrm{Ab}$ decken von Gewinden oder Löchern notwendig ist, bedeuten sie gegebenenfalls auch weniger Handlingaufwand. Das Verfahren ist laut der Holzapfel Group auch geeignet für Anwendungen, die bisher mit schwarzen Zinkschichten oder mit der Kathodischen Tauchlackierung (KTL) ausge-

\section{Ressourceneffizienz schont die}

Ein weiterer großer Vorteil der ultradünn Pulverbeschichtung ist der deutlich eringere Materialverbrauch. Es wird er nicht nur weniger Pulverlack enötigt. Vielmehr werden die ünneren Schichten auch bei iedrigeren Temperaturen einebrannt, was eine weitere Entlastung der Umwelt darstellt. Die ultradünnen

\section{Kontakt}

HOLZAPFEL GROUP

Holzapfel Metallveredelung $\mathrm{GmbH}$

Sinn

oberflaechenspezialist@holzapfel-group.com

www.holzapfel-group.com also auch zu Nachhaltigkeit und Ressourcenschonung bei, indem durch geringeren Pulvereinsatz mehr Materialeffizienz erreicht wird.

Ermöglicht wird die ultradünne Pulverbechichtung, indem die verwendeten Pulerlacke gegenüber den Standardpulvern anderen Rezeptierung hergestellt sigezielle Additive beziehungsweise Binerreichen So können Dünnschichtpulver laut Anbieter bei reduzierter Schichtstärke dennoch eine gute Deckkraft erreichen, die allerdings auch vom gewählten Farbton abhängt. Die feinere Vermahlung verringert die groben Anteile des Kornspektrums ermöglicht dadurch physikalisch dün-

\section{Literaturhinweis}

tung, 2010 